\title{
The Virtual Reality as a tool to analyze modifications in the architecture of the city. Case study: the historical center of the city of Belém-Pará.
}

\section{SIGRADI2018 TECHNOPOLITICAS \\ xxii congresso da sociedade iberoamericana de gráfica digital 22th conference of the iberoamerican society of digital graphics 07|08|09|novembro|2018 iau usp | são carlos | sp br}

\author{
Emerson Bruno de Oliveira Gomes \\ Faculdade de Arquitetura - Universidade de Lisboa | Portugal | b.emersongomes@gmail.com
}

Rodrigo Carlos da Silva Machado

Pontifícia Universidade Católica - PUC Paraná| Brazil | rodrigo.cs.machado@gmail.com

Cristiani Machado Gomes

Universidade Federal do Pará | Brazil | cristiani.machado33@gmail.com

Luis Gustavo de Souza Xavier

Faculdade de Arquitetura - Universidade de Lisboa | Portugal | luisgxavier@gmail.com

\begin{abstract}
This paper presents the partial results of a research that experiments the use of Virtual Reality $(V R)$ in the analysis of future interventions in the architecture of the city of Belém. The objective was the virtual reconstruction of part of the port area of the city, as it was about 100 years. The methods include a historical survey of the site, visits to obtain photographs and measurements, as well as the digital reconstruction of buildings (external faces only). The experiment used Sketchup software for modeling, Unity 3D for rendering and navigation, and HTC Vive glasses for immersion.
\end{abstract}

Keywords: Virtual reality; Architecture; History; Engine games.

\section{INTRODUÇÃO}

A preservação do patrimônio histórico e cultural é um problema latente em diversos lugares do mundo, especialmente em países periféricos como o Brasil, que com seus 500 anos, já perdeu muito de seus bens arquitetônicos nas mais diversas cidades históricas existentes, pelos mais variados motivos.

O uso de tecnologias virtuais para a reconstrução de bens imóveis tombados é uma forma de contribuir para que a informação documental de uma dada época não se perca com uma eventual demolição do edifício ou área urbana (Eliseo, Pacheco, Lopes, \& Silveira, 2009). Tal reconstrução pode tornar-se ainda mais relevante se considerar, como fundamento, o resgate de documentos contendo dados confiáveis que permitam a recomposição de imóveis já inexistentes ou fortemente modificados. Essa busca pela reconstituição virtual de lugares já desaparecidos deu origem ao objetivo da presente pesquisa, que visa, entre outros, resgatar informações físicas acerca de parte do Centro histórico da cidade de Belém.

Pretende-se aqui remontar especificamente o período entre 1870 e 1910, quando o "boom" da borracha (época em que a cidade de Belém estava entre as mais ricas do país) permitiu que diversas intervenções urbanas fossem realizadas (Sarges, 2002), incluindo a zona portuária, que existe e funciona até os dias de hoje, porém com inúmeras modificações e grande parte do seu entorno marginalizado.

O resgate de edifícios e áreas urbanas históricas, mais precisamente a reconstrução virtual de espaços tal como eles eram no passado, oferece a possibilidade a pessoas de todas as idades, de vivenciar realidades hoje inexistentes, palpáveis apenas através de leituras ou fotografias, e em alguns poucos casos, através da cinematografia. Por este motivo escolheu-se a Realidade Virtual, por tratar-se do meio pelo qual é possível experimentar de modo imersivo e interativo uma realidade do passado, construída virtualmente.

Assim, este artigo apresenta, como resultado parcial de uma pesquisa mais ampla, a viabilidade do uso da ferramenta RV na reprodução e experimentação de espaços históricos hoje inexistentes ou significativamente modificados. O hardware escolhido para esta experiência é um HMD (Head Mounted Display - também conhecido como óculos de Realidade Virtual), que permite ao usuário uma experiência imersiva com os movimentos naturais da cabeça e do corpo, inclusive abaixar-se, erguer-se, andar, entre outros.

Como expectativa mais ampla, espera-se que o estudo possa contribuir na atividade dos órgãos fiscalizadores no tocante às tomadas de decisões sobre possíveis modificações arquitetônicas e urbanas, principalmente em áreas sensíveis como os Centros históricos.

\section{BELÉM DA BELLE-ÉPOQUE}

O município de Belém, fundado em 1616, é uma das capitais estaduais mais antigas do Brasil, e possui ainda hoje em sua paisagem as marcas de uma época de intensas intervenções urbanas, fruto do planejamento, construção e implantação de infraestrutura física e sanitária, aos moldes do que, à época, foi realizado nas principais capitais europeias, especialmente Paris. Trata- 
se do período denominado Belle-Époque, ocorrido entre as décadas 1870 e 1910 (Sarges, 2002).

As riquezas advindas do chamado boom da exportação da borracha ocorrido especialmente na Amazônia do final do século XIX, financiaram grande parte das obras descritas no parágrafo acima, dentre elas citam-se: o alargamento de ruas como a Avenida Presidente Vargas e o Boulevard Castilhos França; a construção de prédios em arquitetura eclética como o palacete Bolonha (Lobato, Arruda, \& Ramos, 2005) e o Bibi Costa; a importação de edifícios préfabricados em ferro como o Mercado do Ver-o-Peso e caixa de água de São Braz (em funcionamento até os dias de hoje); a remodelação física de praças inspiradas nos jardins europeus como a Batista Campos e praça da República (Soares, 2008), entre muitos outros exemplos de obras executadas naquela época que constituem, na Belém atual, além de patrimônio histórico, marcos visuais que conferem identidade à cidade.

Outras intervenções que imprimiram fortes mudanças na arquitetura da cidade da época, e que permanecem relevantes até os dias de hoje foram os edifícios em arquitetura eclética influenciada pelas construções europeias. Incluem-se aqui as estruturas em ferro préfabricadas e importadas de países como França e Inglaterra, em estilo art nouveau.

Nesta mesma linha, a área do porto fluvial de Belém tornou-se, à época, uma das maiores prioridades municipais de modernização, visando, com isso, atender às exigências necessárias ao escoamento da produção da borracha, bem como receber os artigos importados amplamente consumidos pela elite. Tal área foi alvo das mais relevantes intervenções urbanísticas daquele século, modificando significativamente o traçado urbano e a arquitetura da cidade (Sarges, 2002). Seu funcionamento nos dias atuais ainda ocorre com atividades portuárias, acrescido de comércio e turismo.

Pelos motivos acima, selecionou-se como estudo de caso o Centro Histórico de Belém, mais precisamente a área portuária, hoje parcialmente degradada e alvo de constantes intervenções nos prédios em razão da necessidade de reabilitá-los.

\section{OBJETIVOS}

O objetivo geral deste artigo é apresentar a reconstrução virtual de uma parte do Centro Histórico da cidade de Belém no período compreendido entre 1870 e 1910, com vistas à utilização da tecnologia RV como meio para possibilitar a experimentação do lugar, tal como já foi um dia. Os objetivos específicos envolvem pesquisar sobre a história de Belém, e sobre os atuais métodos de construção e visualização de cenários virtuais imersivos através do uso de óculos de RV.

\section{METODOLOGIA}

Os métodos adotados abrangem quatro etapas: a primeira ocorreu a partir do levantamento bibliográfico sobre a arquitetura de Belém no período entre o final do século XIX e início do $X X$, bem como acerca dos atuais recursos de tecnologia de visualização em VR. As pesquisas se deram por meio de livros, dissertações de mestrado, teses de doutorado, artigos científicos, mapas e websites sobre ambos os temas.

Na segunda etapa optou-se por abordar a área portuária. Inicialmente realizou-se a delimitação do espaço a ser reconstruído virtualmente, em seguida visitou-se o local para fotografar as fachadas, o mobiliário e as texturas das edificações, bem como obter medidas de largura e altura de alguns prédios que seriam utilizados como referência para os demais.

Na terceira etapa ocorreu a produção do modelo virtual utilizando-se as informações da pesquisa histórica e as medidas obtidas através dos levantamentos realizados no local. Limitou-se a reconstruir tão somente as cascas externas das edificações e as áreas urbanas de entorno, incluindo a representação das águas da baía do Guajará.

Ainda nesta etapa foram utilizados como softwares o Sketchup@ para modelagem, o Unity 3D@ para aplicação de materiais, iluminação e programação das ações em Realidade Virtual, o Adobe Mixamo@ e o Adobe Fuse CC ${ }^{@}$, para criação e animação dos personagens. Todos os softwares foram utilizados com licenças gratuitas.

$\mathrm{Na}$ quarta e última etapa, realizaram-se os testes em VR utilizando-se os óculos HTC Vive. Tal sistema permitiu que o usuário pudesse movimentar-se caminhando normalmente por uma área de aproximadamente $3,5 \times 3,5 \mathrm{~m}$, oferecendo os chamados 6DOF - Degree of Freedom (6 Graus de liberdade), o que resulta em uma movimentação livre, tanto da cabeça quanto do corpo, em uma área de aproximadamente $12 \mathrm{~m}^{2}$.

\section{A ARQUITETURA DO BAIRRO HISTÓRICO DA CIDADE DE BELÉM}

Grande parte do traçado municipal urbano nos dias atuais é fruto do planejamento e reformas realizadas no período entre 1870 e 1912, principalmente na administração do Intendente municipal Antônio Lemos, cujas obras, além de remodelar a área adjacente ao porto, se expandiram para localidades mais afastadas do centro, consideradas subúrbios e áreas rurais (Sarges, 2002).

O projeto urbanístico de Lemos, em primeiro lugar atendia às exigências comerciais, a exemplo do escoamento da produção da borracha. Assim, o porto tornou-se um ponto fundamental no plano de desenvolvimento da cidade, bem como as vias urbanas para transportar e armazenar produtos que chegavam e saiam do município.

Os mapas abaixo apresentam o traçado da cidade em três momentos: Figura 01 - antes das obras do porto; Figura 02 - o projeto de modernização de Lemos (em vermelho); Figura 03 - Imagem de satélite dos dias atuais.

Observando as imagens, verifica-se a intensão de criar uma paisagem urbana com ares modernos principalmente para pessoas que estivessem chegando, já que esta era a principal porta de acesso à Belém. As obras do porto, a remodelagem de praças e as novas edificações imprimiam aos visitantes a leitura de cidade desenvolvida, com vistas amplas e edifícios que impunham significativas modificações no cenário da cidade (Sarges, 2002). 


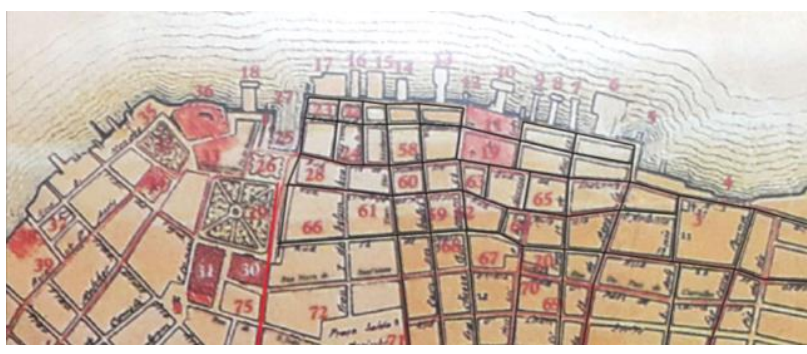

Figura 01: Mapa da cidade de Belém, elaborado em 1905. Zona portuária da cidade. Ao norte da imagem aparecem os antigos trapiches, demolidos por ação das obras de construção do porto. Fonte: (Silva, Fernandes, \& Miranda, 2014).

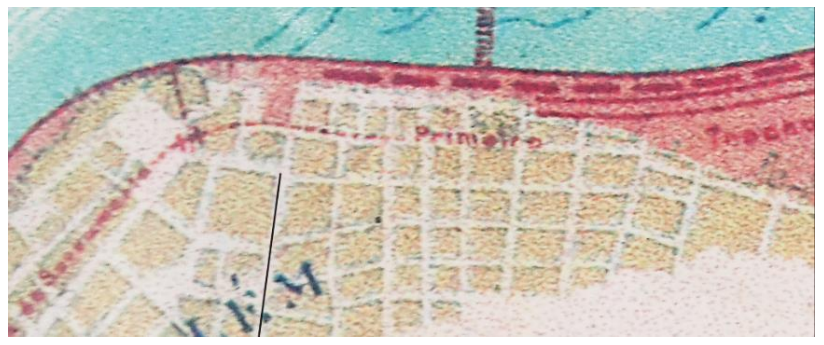

Figura 02: Projeto de construção da obra do "Port of Pará". Data provável 1906. Em vermelho percebe-se a área dos antigos trapiches aterrada e os primeiros galpões metálicos importados da Europa. Fonte: (Museu da Estação das Docas, 2016).

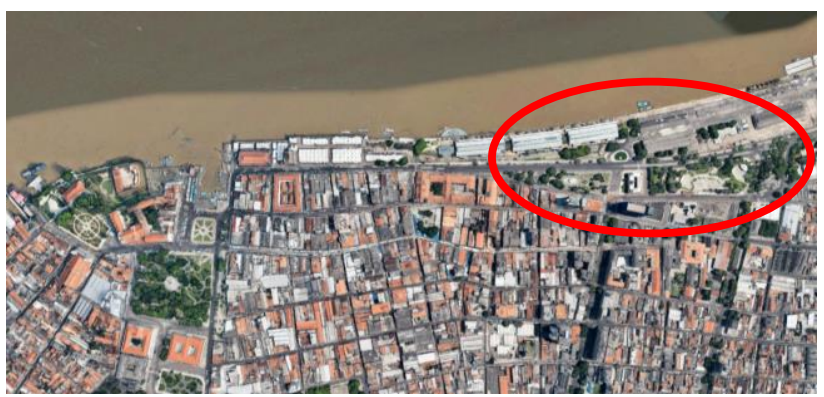

Figura 03: Imagem referente aos dias atuais, com o aterro e os galpões executados. Na área circulada, o Boulevard da República. Fonte: (Google Maps, 2018)

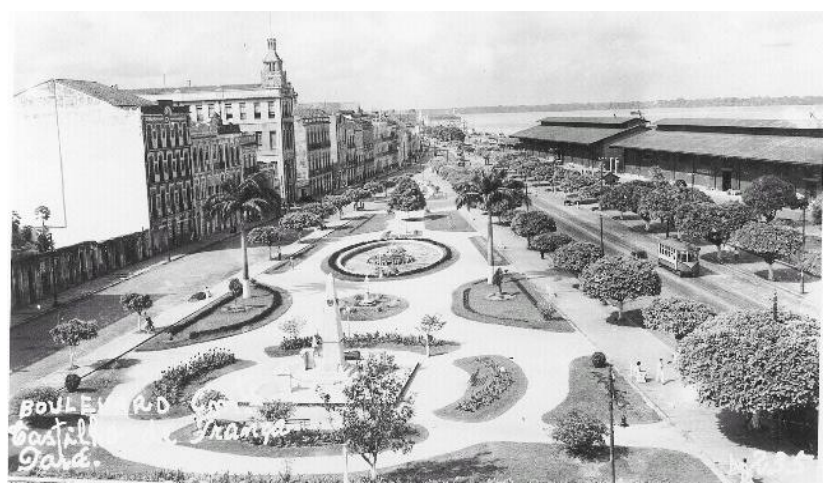

Figura 04: Imagem do Boulevard da República (Avenida Castilho França), data aproximada, 1910. À esquerda percebem-se os galpões já executados, à direita as edificações, hoje parcialmente modificadas. Fonte:(Silva et al., 2014).

Nas proximidades do Porto, em razão das atividades comerciais que ele atraia, foram alargadas ruas e avenidas, planejadas, à época, em longas distâncias, de modo a facilitar o escoamento dos produtos, conforme é exibido na figura 04. (Soares, 2008).

\section{REALIDADE VIRTUAL E ARQUITETURA}

O tema Realidade Virtual teve origem no final da década de 1950 e início dos anos 1960, com invenções de equipamentos de diversão como o Sensorama (Ellis, 1991). Em 1965 Ivan Sutherland propôs o The Ultimate Display, um equipamento similar aos atuais óculos de VR (Sutherland, 1965, 1968).

Nos anos seguintes expressões como Realidade Artificial (Krueger, Gionfriddo, \& Hinrichsen, 1985) e Ciberespaço (Gibson, 1984) ganharam força, mas foi ainda na década de 80 que Jaron Lanier cunhou o termo Realidade Virtual (Machover \& Tice, 1994; Steuer, 1993), visando diferenciar as simulações tradicionais dos mundos virtuais por ele estudados (Machado, 1995).

Posteriormente vários outros autores atuaram na área, especialmente na década de 90, quando diversos conceitos e tecnologias foram desenvolvidos sobre 0 assunto (Witmer \& Singer, 1998).

Atualmente é comum encontrar a aplicação da Realidade Virtual nas mais diversas áreas do conhecimento, como medicina, engenharia, arquitetura, psicologia, entre outros. Seu uso possibilitou, por exemplo, treinamento de pessoas em atividades perigosas, bem como o acompanhamento, em laboratório, do comportamento de seres humanos realizando determinadas atividades.

Similarmente a esta pesquisa, Eliseo e colegas desenvolveram em 2009 um modelo imersivo para o edifício Makenzie, em São Paulo, erguido em 1984 para abrigar a escola de engenharia, com vistas a preservação documental do edifício (Eliseo et al., 2009). Mais recentemente, em Bandung, na Indonésia, autores remodelaram a Rua Braga, integrante do distrito histórico e colonial da cidade, com vistas a testar modificações em edifícios ao longo da rua, bem como auxiliar na determinação de regulamentações legais específicas (Agirachman et al., 2017).

No presente trabalho, adotaremos o conceito de Rebelo sobre o tema, que propõe a VR como uma maneira de transportar uma pessoa para uma realidade (um ambiente virtual) em que ela não está fisicamente, mas sente como se estivesse ali (Rebelo, Noriega, Duarte, \& Soares, 2012).

\section{A DELIMITAÇÃO DA ÁREA}

A escolha do local para construção do modelo virtual se justifica em razão da área portuária ter sido o principal alvo das intervenções urbanísticas modernizadoras implantadas em Belém no período pesquisado, cuja arquitetura, apesar de posteriores modificações, ainda se mantém em parte.

Assim, para limitar o espaço virtual a ser construído escolheu-se, dentro da zona portuária, a extensão da atual Avenida Boulevard Castilho França até a Companhia das Docas do Pará (CDP) antiga "Port of Pará", conforme as Figuras 05 e 06. 


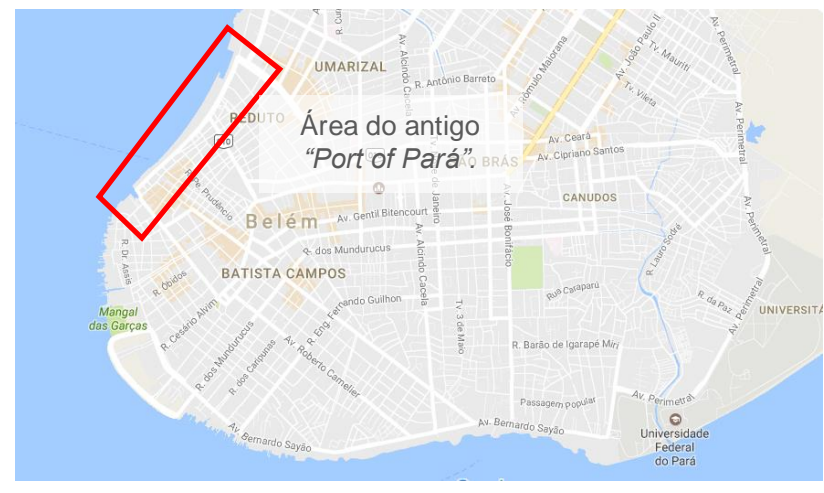

Figura 05: Mapa atual da cidade de Belém, com a demarcação da área foco da pesquisa. Fonte: (Google Maps, 2018).

O trecho escolhido inclui edificações historicamente conhecidas como o mercado de peixe do Ver-o-Peso, o mercado de carne, o prédio do Solar da Beira, entre tantos outros que compunham o panorama urbano da cidade no início do século XX.

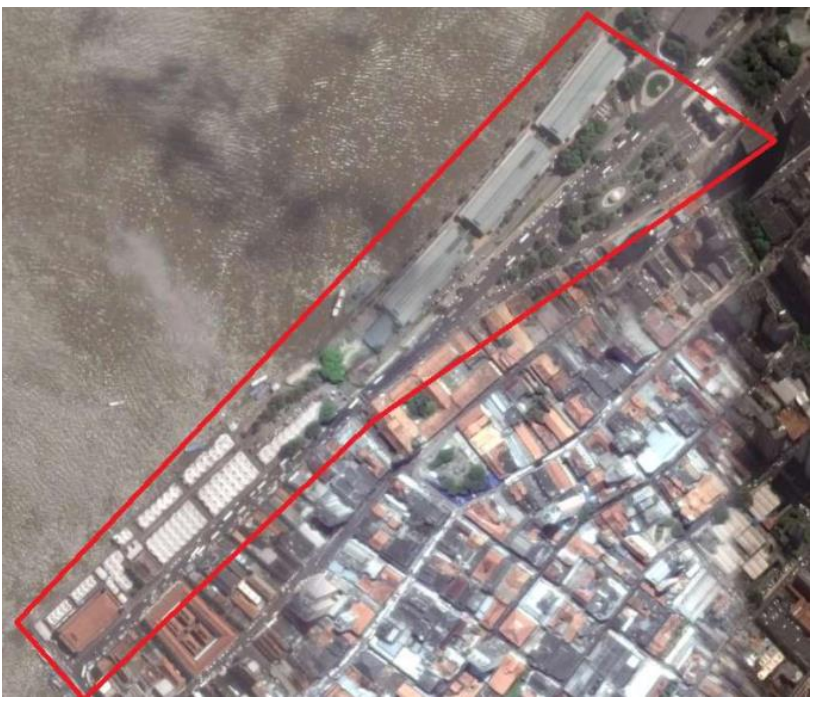

Figura 06: Mapa atual da cidade de Belém, com a demarcação da área foco da pesquisa. Fonte: (Google Maps, 2018).

\section{A PRODUÇÃO DO MODELO VIRTUAL}

Após a coleta de informações históricas e dados métricos das edificações atualmente existentes, utilizou-se o software Sketchup para realizar todas as modelagens. Primeiro construiu-se no computador separadamente cada prédio da Avenida Castilho França (Figura 07).

Em seguida, a partir das fotografias e descrições, foram recriados os equipamentos urbanos, como as praças existentes no Boulevard, calçadas, entre outros. (Figura 08). Em seguida foi realizada a locação das edificações nos seus devidos locais. Tal locação necessitou de um estudo criterioso das fotografias, de modo que fosse possível identificar os prédios existentes em relação àqueles que já foram demolidos.

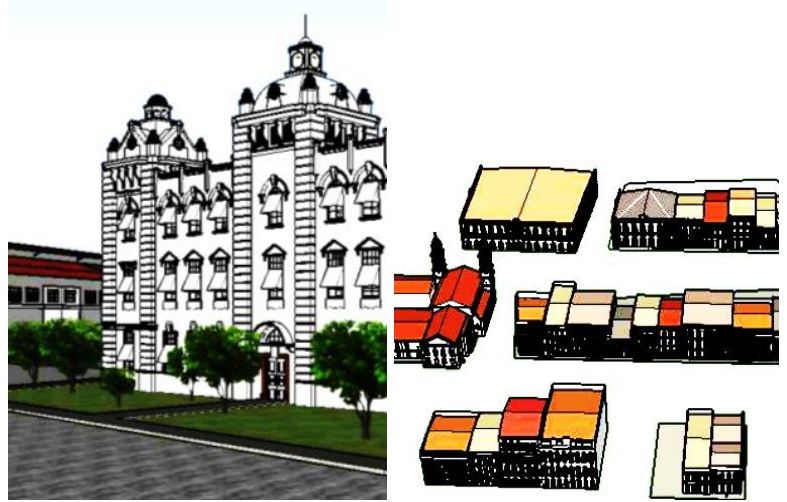

Figura 07: Edificações da área em estudo, reconstruídas em meio virtual. Fonte: o autor, 2017.

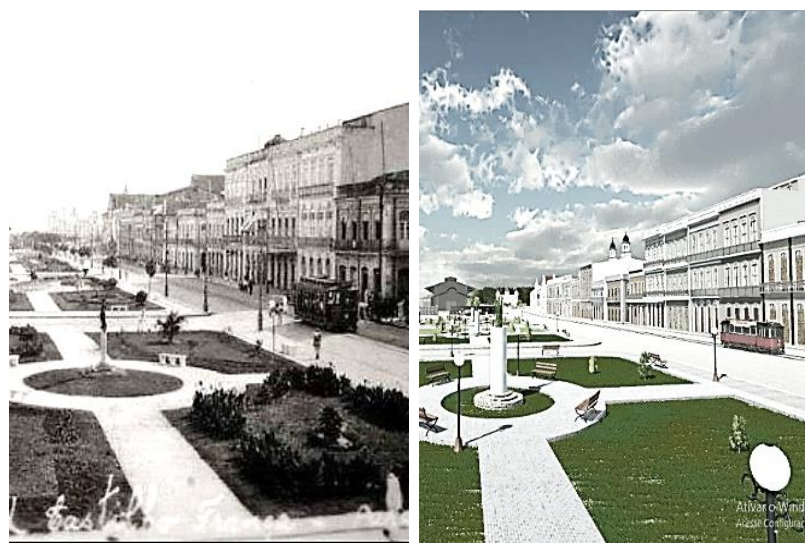

Figura 08: Na esquerda, uma fotografia do Boulevard da República, data aproximada 1910, exibindo parte da área a ser reconstruída. Na direita, o mesmo local, reconstruído virtualmente. Fontes: Imagem da direita - (Silva et al., 2014); Imagem da esquerda: o autor, 2017.

Uma vez modelado o cenário, realizou-se a exportação para o software Unity, esta engine dispõe de diversos recursos para o aperfeiçoamento da qualidade das imagens, o que permitiu a criação e adaptação necessárias para que as texturas exibidas fossem, na medida do possível, aproximadas das fotografias e descrições históricas, imprimindo-lhes boa semelhança com a época.

Como o processo de renderização do software escolhido ocorre em tempo real, foi possível fazer uso das chamadas texturas dinâmicas, que oferecem a vantagem de movimentarem-se durante a visualização, a exemplo das ondas nas águas, do efeito dos ventos na grama, nuvens, árvores, entre outros. Este recurso ajuda a oferecer maior realismo na visualização, e consequentemente na sensação de imersão por parte do usuário. Entretanto, é coerente que haja cuidado no uso, pois o excesso pode acarreta em lentidões e incômodos na exibição.

Em seguida iniciou-se a produção dos personagens que dariam vida às ruas e praças modeladas, um dos exemplos consta na Figura 09. A principal fonte de informações sobre a vestimenta e o modo de viver das pessoas da época foi Sarges, (2002), a partir de suas referências, utilizou-se o programa Adobe Mixamo para modelagem, texturização e movimentos das pessoas, em sua versão gratuita. No Unity cada personagem foi programado para 
realizar um movimento específico, com o intuito de dar a sensação de naturalidade ao ambiente.
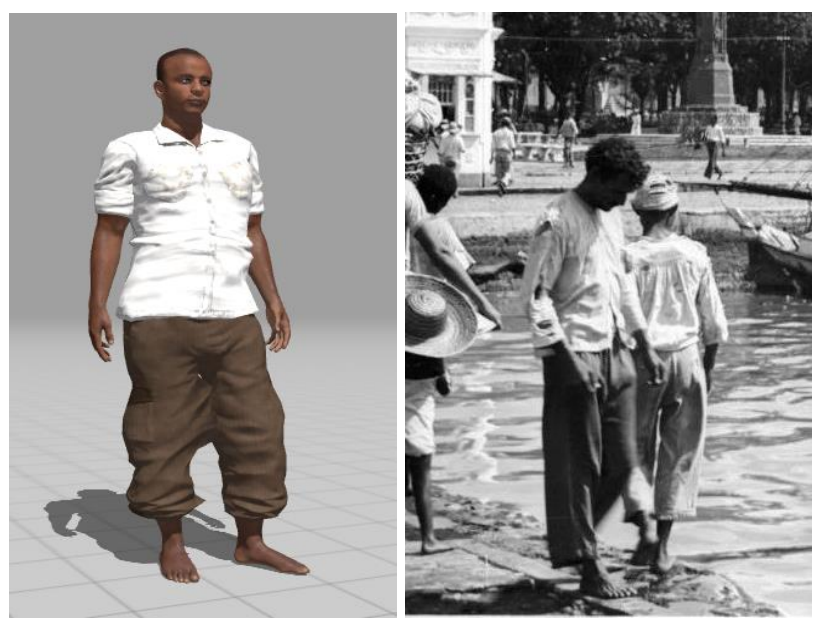

Figura 09: Na esquerda, um personagem construído e animado virtualmente através do software Adobe Mixamo@ ${ }^{\circledR}$, inspirado na figura humana presente na fotografia da direita. Fonte: imagem da direita: (Silva et al., 2014); imagem da esquerda: o autor, 2017.

A última etapa do desenvolvimento do trabalho consistiu em adaptar o cenário arquitetônico da cidade para o formato VR, o qual faz uso do equipamento denominado óculos de realidade virtual, destinado a visualizar e explorar o lugar criado, para tanto, utilizou-se a ferramenta Steam VR plugin.

O equipamento escolhido para permitir a imersão no modelo virtual foi o HTC Vive, óculos VR que acompanha dois sensores de movimentos a laser. Dispostos a determinada distância os sensores reconhecem os óculos, permitindo o deslocamento do usuário em todos os sentidos, incluindo o giro da cabeça.

\section{RESULTADOS}

O cenário foi completamente construído em meio virtual, praticamente todas as edificações significativamente não preservadas possuíam alguma fotografia da época, o que permitiu realizar a reconstrução desta etapa do trabalho.

Como trata-se de um percurso que pode ser visto em 360 graus, em cada esquina foi necessário produzir uma continuidade do quarteirão, com vistas a dar seguimento à visão da quadra.

As texturas da água e da grama foram configuradas como dinâmicas, dando a sensação de movimento. Esta decisão aumentou o realismo, mas terminou por provocar um certo incômodo nos usuários devido à lentidão ao aproximar-se destes elementos.

Por tratar-se de um sistema que permite ao usuário circular por uma área com cerca de $12 \mathrm{~m}^{2}$, recorreu-se ao recurso de teletransporte para que o usuário pudesse percorrer 0 cenário inteiro. Assim, além de caminhar naturalmente pelo espaço físico de $3,5 \times 3,5 \mathrm{~m}$, foi ainda possível que participante apontasse o joystick em uma direção e, com um laser virtual, indicasse o local para onde pretendia ser teletransportado. Assim ele desaparecia do local onde estava e surgia no lugar para o qual estava apontando o laser.

Por fim o modelo se mostrou apto a experimentações virtuais, com possibilidade de navegação por toda área, permitindo a visualização dos prédios e dos espaços urbanizados, em acordo com os dados históricos identificados.

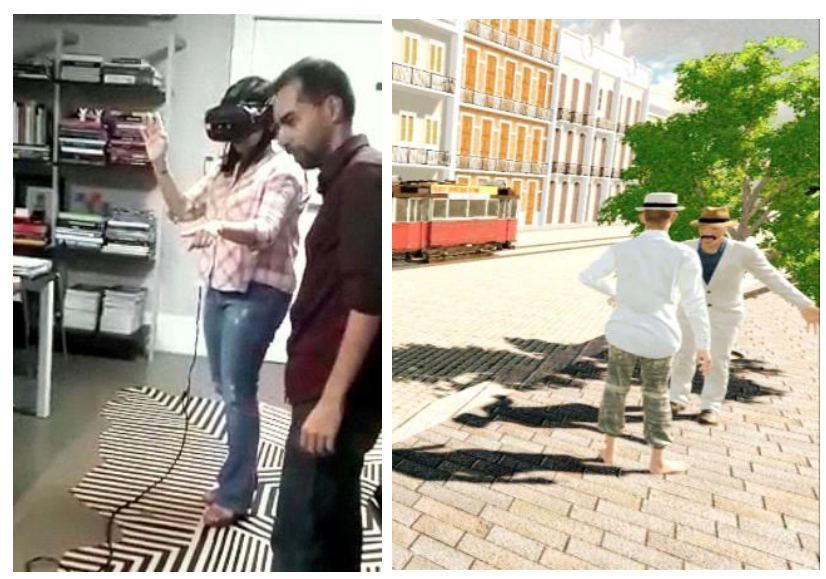

Figura 10: Na esquerda, dois professores realizando os primeiros testes no cenário. À direita, uma cena observada pelo usuário, em modo imersivo. Fonte: o autor, 2017.

\section{DISCUSSÕES}

Alguns alunos e professores do curso de arquitetura e urbanismo puderam experimentar preliminarmente os ambientes em VR. Não foram ainda coletadas informações estatísticas, apenas observações relacionadas às reações dos usuários, que se mostraram bastante entusiasmados com a possibilidade de vivenciar o espaço já conhecido, mas que agora apresentava-se com características de aproximadamente 100 anos atrás.

Não foram percebidas dificuldades na locomoção pelo cenário, porém ainda era nítida a latência em algumas partes, o que tornou a experiência pouco fluida em certos trechos. Uma das partes mais observadas era a presença dos personagens no cenário, principalmente por serem vistos na escala 1:1.

As impressões verificadas no modelo criado mostram-se com grande utilidade na percepção espacial da área, permitindo inevitáveis julgamentos relacionados ao que existe nos dias atuais. Posteriormente espera-se acrescentar no cenário virtual itens como 0 som tridimensional, falas dos personagens e movimento dos bondes elétricos.

Foi sugerido por um dos professores a construção virtual da mesma área, mas com as características atuais, de modo a facilitar as comparações e as observações das intervenções e degradações sofridas. Baseado nisso, uma sugestão para pesquisas futuras é a utilização de sistemas de nuvem de pontos via fotografias por drones. A malha criada desta forma pode-se sobrepor ao modelo virtual do passado, permitindo ao usuário a troca de cenário com o apertar de um botão, indo e voltando no tempo, em escala real. 
Quanto à utilização do modelo para auxiliar em casos de restauro de fachadas, observou-se que seriam necessárias modificações na maquete a fim de que estas se tornem mais fiéis aos originais, como a reprodução de alguns azulejos com desenhos exatamente iguais aos que ornamentam alguns casarões, bem como a implementação de detalhes omitidos em razão do peso do arquivo. Aqui há a sugestão da realização da construção do volume utilizando-se tecnologias como o escâner a laser, que permite precisão milimétrica no levantamento e construção em 3D.

Foi observada a inexistência de informações básicas acerca dos prédios, como ano de fundação, de modificação, restauração ou demolição, a quem pertenceu e a quem pertence nos dias atuais, os responsáveis pelo projeto/construção, bem como esclarecimentos acerca da arquitetura adotada e da origem dos materiais importados.

Recomendou-se a inserção de tais informações no modelo, estas poderiam ser acessadas pelo usuário com apenas um clique, ressaltando que tal adição dará maior valor acadêmico ao trabalho enquanto ferramenta utilizada na educação. Um dos professores sugeriu ainda sua doação à museus e órgão voltados ao ensino da história de Belém.

Foi ainda questionado acerca do cronograma de expansão do modelo para englobar outras áreas do município, o que possibilitaria a investigação das modificações propostas quando de seu licenciamento pela prefeitura, bem como um estudo mais apurado para se determinar as diretrizes do planejamento urbano da cidade, sendo possível observar, mesmo antes de construído, que impacto visual prédios de determinada altura poderiam causar ao seu entorno, ou até mesmo se seriam vistos a partir de determinadas áreas. Assim, as modificações na paisagem da cidade ocorreriam primeiramente na Belém virtual, para que se pudesse investigar suas implicações no modelo real.

\section{AGRADECIMENTOS}

Aos Professores Francisco Agostini e Francisco Rebelo pela paciência e por apoiarem o tema da pesquisa. À Professora Marcia Nunes, pela parceria.

\section{REFERÊNCIAS}

Agirachman, F. A., Ozawa, Y., Indraprastha, A., Shinozaki, M., Debora, I., Sitompul, M., ... Zefanya, T. (2017). REIMAGINING BRAGA Remodeling Bandung's Historical Colonial Streetscape in Virtual Reality. CAADRIA, 23-33. Retrieved from http://papers.cumincad.org/data/ works/att/caadria2017_147.pdf

Eliseo, M. A., Pacheco, B. de A., Lopes, F. S., \& Silveira, I. F. (2009). Visualização imersiva do patrimônio histórico: Um modelo espaço-temporal para o campus Mackenzie-Itambé.
In SIGRADI. São Paulo. Retrieved from http://papers.cumincad.org/data/works/att/sigradi2009_615.c ontent.pdf

Ellis, S. R. (1991). Nature and origins of virtual environments: a bibliographical essay. Computing Systems in Engineering, 2(4), 321-347. https://doi.org/10.1016/0956-0521(91)90001-L

Gibson, W. (1984). Neuromancer (Edição rei). Ace. Retrieved from https://www.amazon.com/Neuromancer-WilliamGibson/dp/0441007465/ref=sr 11 ? s=books\&ie=UTF8\&qid= $1524878572 \& s r=1-1 \&$ keywords $=$ neuromancer

Google Maps. (2018). Área portuária da cidade de Belém. Retrieved July 2, 2018, from https://www.google.com/maps/@-1.4404293,$48.5023541,14.75 z$

Krueger, M. W., Gionfriddo, T., \& Hinrichsen, K. (1985). VIDEOPLACE---an artificial reality. Proceedings of the SIGCHI Conference on Human Factors in Computing Systems $\begin{array}{cccc}\text { CHI } & \text { '85, } & \text { (April), } & 35-40 .\end{array}$

Lobato, C. C. de Q., Arruda, E. S., \& Ramos, A. H. G. (2005). Palacete Bolonha - uma promessa de amor, 75. Retrieved from https://fauufpa.files.wordpress.com/2011/05/livrobolonha1.pdf

Machado, L. dos S. (1995). Conceitos Básicos Da Realidade Virtual. Retrieved from http://www.di.ufpb.br/liliane/publicacoes/1995_rt.pdf

Machover, C., \& Tice, S. E. (1994). Virtual Reality, 4(3). https://doi.org/10.1109 / 38.250913

Museu da Estação das Docas. (2016). Exposição Permanente. Belém.

Rebelo, F., Noriega, P., Duarte, E., \& Soares, M. (2012). Using virtual reality to assess user experience. Human Factors, 54(6), 964-982. https://doi.org/10.1177/0018720812465006

Sarges, M. de N. (2002). Belém: riquezas produzindo a belleépoque (1870-1912). (Paka-Tatu, Ed.) (2a Edição). Belém.

Silva, R. L. da, Fernandes, P. C., \& Miranda, V. C. C. de. (2014). Belém da Saudade: A memória da Belém do início do século XX em cartões postais. (SECULT, Ed.) (4a). Belém.

Soares, K. G. (2008). As formas de se morar na Belém da belle époque (1870-1910). Universidade Federal do Pará.

Steuer, J. (1993). Defining virtual reality: dimensions determining telepresence. Communication in the Age of Virtual Reality, 3356. $\quad$ https://doi.org/https://doi.org/10.1111/j.14602466.1992.tb00812.x

Sutherland, I. E. (1965). The ultimate display. Proceedings of the Congress of the Internation Federation of Information Processing (IFIP), 506-508. https://doi.org/10.1109/MC.2005.274

Sutherland, I. E. (1968). A head-mounted three dimensional display. Proceedings of the December 9-11, 1968, Fall Joint Computer Conference, Part I on - AFIPS '68 (Fall, Part I), 757. https://doi.org/10.1145/1476589.1476686

Witmer, B. G., \& Singer, M. J. (1998). Measuring Presence in Virtual Environments: A Presence Questionnaire. Presence: Teleoperators and Virtual Environments, 7(3), 225-240. https://doi.org/10.1162/105474698565686 